\title{
Does Cultural Hofstede dimension "Indulgence versus Restraint" impact the Corporate Performance
}

\author{
Houda Qasim Aleqedat \\ Doctoral School of Management and Business Administration \\ Hungarian University of Agriculture and Life Sciences Institute of Economics, Hungary \\ Author E-mail: hudaeqedat@yahoo.com
}

\begin{abstract}
A B S T R A C T
Jordan, as an Arab country located in the Middle East, began to pay attention to change. Jordanian society began to move from an old-style state to a contemporary state. Where globalization had a significant impact on culture, either in terms of individual culture and organizational culture. On the other hand, many studies emphasized that culture through its dimensions has an important role in influencing the corporate atmosphere or corporate social responsibility, as well as affecting the financial performance of companies. Moreover, the literature indicates that cultural dimensions influence the conduct of individuals and the performance of firms.

The literature indicated that there are different dimensions of culture, including Hofstede's dimensions of culture, which are Power Distance Index; Individualism versus collectivism; Masculinity versus Femininity; Uncertainty Avoidance index; Long-versus Short- Term Orientation; Indulgence versus Restraint. This study focused on the Indulgence versus Restraint dimension, as a recent dimension, where through the literature it can be predicted the existence of a critical role for the indulgence dimension on performance. After reviewing the literature related to the Indulgence dimension, it was found that there is a shortage and almost no local studies conducted in Jordan regarding the Indulgence versus Restraint dimension. Since this dimension is new, this paper stresses the importance of more research on this subject to expand the local literature on Indulgence and its impact on the performance in the Jordan context and compare it with other countries in order to provide important and useful results for the policymakers.
\end{abstract}

Key word: Corporate Performance, Indulgence Versus Restraint Dimension, Jordanian Society.

Copyright $@ 2021$ Authors. This is an open access article distributed under the Creative Commons Attribution License, which permits unrestricted use, distribution, and reproduction in any medium, provided the original work is properly cited.

\section{INTRODUCTION}

The Jordanian society has begun to enter the circle of modernity and undergoes transitional processes from traditional culture to a culture of openness. Traditional life is usually characterized by harmony and relative harmony in addition to preserving cultural origin. A set of public values is usually transmitted through generations in 
a formal manner through various educational institutions. Which the community has set up for this purpose, such as the school, in informal ways such as the family (Abu Asbah, 2012). This transition from a traditional to a state of modernity and globalization has had a great impact on the individual culture and organizational culture of organizations, and some have considered globalization as a protective shield against many of the challenges faced by organizations and their workers.

The organizational culture (Schein, 1992) refers to concepts, philosophies, concepts, values, assumptions, beliefs, expectations, attitudes and standards. These concepts form the framework that illustrates the way in which the work in the organization should be taught to the new members of the organization as correct ways of perception and thinking. Organizational culture forms the standard patterns of individual behavioral practices and interpersonal relationships that arise between them.

It is clear from a review of literature on the subject of cultural dimensions that there is an impact of cultures on the behavior of individuals, in turn, it has an impact on the performance of companies. This study is a literature review of the previous studies related to the sixth dimension, indulgence versus restraint. It is found that there are few studies in the literature on this subject, and there are no related studies in Jordan. The current study highlights the impact of indulgence on performance, future studies should examine the impact of this dimension on the performance in the Jordan context and compare it with other countries in order to provide important and useful results for the policymakers.

\section{Research Questions (Problem statement)}

The research will answer the key question which is: Does the Cultural Hofstede dimension "Indulgence versus Restraint" influence Corporate Performance?

\section{Research Objectives}

The main purpose of the research is to highlight the impact of Indulgence versus Restraint as a Cultural Hofstede dimension on Corporate Performance.

\section{Research Significance}

The study uses the sixth Hofstede cultural dimension Indulgence versus Restraint to measure the culture. Using this dimension the indulgence and its impact on the corporate performance would contribute to the literature due this topic was not conducted widely in the literature particularly in the Jordan context since it is considered as a new dimension. This study will highlight the important role of indulgence on the corporate performance.

\section{METHODOLOGY}

This paper is a review paper based on published articles and review the present literature related to the paper topic, particularly in Jordan to endeavour to determine the gap in that literature.

\section{Literature Review Culture}

Culture has become an important topic to most researchers these days. it is considered one of the concepts that were used in the past in agricultural topics, and recently appeared in recent Europe in the seventeenth, eighteenth, and nineteenth centuries, and began to be practiced in non-agricultural subjects such as the education of persons, global human capability, national standards, and ambitions (Yaşar, 2014). Culture expresses the different behaviors of people across countries. This difference explains the difference in views on some topics.

Culture, in the narrow definition, in Europe means "civilization", education, art, and literature. Whereas the broader definition meaning of 'culture' means perceptual software. Culture shows social patterns such as thinking, sense, and behaving, as well as other behaviors such as greeting, eating, and viewing feelings. Culture expresses the patterns of a group of people such 
as language, clothing, social values, philosophies, social behaviors, talents. These groups that represent a particular country impact the culture.

There are multiple definitions of culture, (Hoebel, 1966) defines culture as mental programming that characterizes the members of society by Hofstede. Hofstede developed Hofstede's model to understand the different cultures across countries.

The following figure shows Hofstede`s Onion Model of Culture.

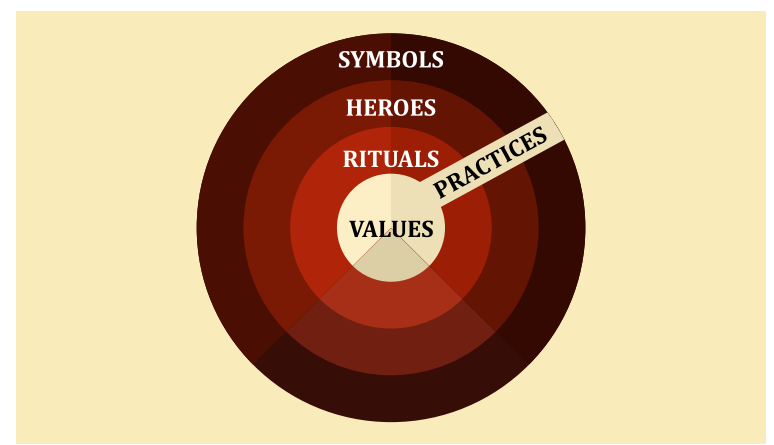

Figure 1. Illustration of Culture Onion Model

Source: Hofstede; Minkov (2010), Cultures and Organizations: Software of the Mind 3rd Edition, McGraw-Hill

This model consists of four elements (Symbols, Heroes, Rituals, and values). Values are the most representative of manifestations of culture and symbols are the least representative of manifestations of culture. The culture of each country is characterized by certain symbols (objects, words, images, signals) (Hofstede and Minkov, 2010). Heroes are considered role models and appreciated in every society. In Jordanian culture, there is more than one hero and a heritage figure known over time, including Mustafa Wahbi al-Tal, one of the most famous poets in Jordan at all, and one of the stallions of contemporary Arab poetry, he was called the poet of Jordan, and Arar. In his poetry, quality and sobriety, anti-injustice, and anti-colonialism.

With regard to Rituals, they represent habits within the culture of each country, such as greeting, farewell, and celebration of occasions. Jordan has distinctive and inherited social habits and traditions. It is practiced by individuals and groups frequently, and which society imposes on its members, so they cannot deviate from it and violate it, such as the customs of hospitality, and the habit of giving gifts on various social occasions. Social habits should be congruent with positive social values, that is, values that people desire and love. There are acceptable social habits practiced by individuals and groups in our Jordanian society, such as the habit of cooperation, and among the good social habits in Jordan is the habit of hospitality, and this habit is represented in receiving the guest with cheerfulness and openness, and the host offering his guest whatever food is available. There is also the habit of kissing the cheeks and shaking hands.

Furthermore, Generosity and hospitality in Jordanian society are some of the most prominent social and intrinsic values.

The base of building this model values, which are located in the centre, these values which individuals learn from childhood. Where values are built at the age of ten, and after that these beliefs cannot be changed. These social values, are the preferred thing, or any judgment we give about something, and value is something desirable at the individual and collective levels. Values direct human behavior, and regulate his relationships with others and with reality itself.

The current study tries to highlight the impact of Indulgence versus Restraint as a Cultural Hofstede dimension on Corporate Performance.

\section{Differences between cultures}

Globalization is considered one of the most important events that have been at the forefront of the world for a long time until this moment, as countries have become open to each other, as globalization has led to companies' interest in internationalization and growth, and this has led to an increased interest in conducting research related to intercultural communication. Since most of the major companies have branches in different parts of the world, so besides paying attention to financial prosperity, it is necessary to 
take into account the importance of intercultural communication especially that they have business partners whose culture differs from their own.

\section{Hofstede cultural Dimensions}

Hofstede is the founder of the Hofstede cultural dimensions model. Where he indicated that culture has a role in impact on the values of society. Furthermore, culture is scope for intercultural connection. Thus, the Hofstede Model is a structure that helps organizations crosswise cultures work together more effectively. Hofstede developed the five cultural dimensions, namely: power distance, individualism-collectivism, masculinity-femininity, uncertainty avoidance. Long-term orientation vs. short-term orientation (LTO), later the sixth cultural dimension has been developed recently that known of Indulgence vs. restraint (IND). The latter dimension was added by Hofstede and Minkov in 2010 (Hofstede \& Minkov, 2010).

\section{Indulgence vs. restraint (IND) definition}

The indulgence vs. restraint (IND) represents the independent preferences that distinguish countries from each other. Indulgence society allows gratification human desires related to the enjoyment of life (caring about the satisfaction of needs). While the restraint society restricted and controlling the satisfaction of needs (rescinds meeting needs and cares about strict social standards) (Hofstede, 2010). In other words, the Indulgent cultures focus on happiness, positive feelings, easily expressed, and well-being, care about free time and individual freedom. These things do not exist in restricted societies.

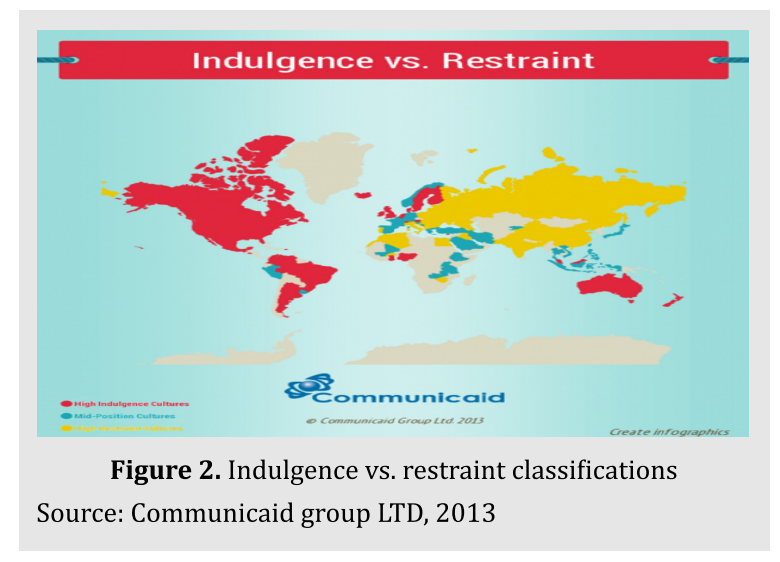

It is a new dimension, it was derived from the literature of "happiness". Which is essentially linked to the national levels of self-happiness and control of life. Created by Michael Minkov to cover social variances shown by the World survey of values (WVS) for representative samples of 93 societies, and it is unsolved by Hofstede's other five dimensions.

It's somewhat matching with the long-term versus the short-term but in a poor way. It's covered the other sides which are not covered by the other dimensions. This dimension scores in 93 countries (Hofstede, 2011). Figure (1) indicates that the indulgent culture in South and North America, Western Europe, and some regions in Sub-Sahara Africa. On the contrary, Eastern Europe, Asia, and the Muslim world are considered a restraint culture. The following figure (2) indicates the differences between Indulgent and Restrained Societies.

\section{Empirical Studies (The relationship between the Indulgence and Corporate Performance)}

There are rare studies conducted on the sixth dimension, due to it is considered a new dimension, and in particular, there were no studies linked this dimension to the performance of the company directly.

(Sun and et al., 2018) investigated the effect of indulgence versus restraint (IND) as a moderating variable on the relationship between corporate social performance (CSP) and corporate financial performance (CFP). The study found that in indulgent countries the social performance effect positive on financial performance but in a weak way. According to (Shi and Veenstra, 2015) in high indulgent countries if the companies have high CSP the governing legality would lower levels. Therefore, the CSP interacted with indulgence will negatively influence on CFP. Conversely, in high indulgent countries, a high CSP leads to an absence of prospects of shareholders, so the interaction between CSP and indulgence will positively influence on CFP. (Oliveira, 2016) indicated a higher dividend payout in countries with a high level of indulgence. 


\begin{tabular}{ll}
\hline Indulgence & Restrained \\
\hline Higher percentage of people declaring themselves very happy & Fewer very happy people \\
\hline A perception of personal life control & $\begin{array}{l}\text { A perception of helplessness: what happens to me } \\
\text { is not my own doing }\end{array}$ \\
\hline Freedom of speech seen as important & Freedom of speech is not a primary concern \\
\hline Higher importance of leisure & lower importance of leisure \\
\hline More likely to remember positive emotions & Less likely to remember positive emotions \\
\hline In countries with educated populations, higher birthrates & In countries with educated populations, lower birthrates \\
\hline More people actively involved in sports & Fewer people actively involved in sports \\
\hline In countries with enough food, higher percentages of obese people & In countries with enough food, fewer obese people \\
\hline In wealthy countries, lenient sexual norms & In wealthy countries, stricter sexual norms \\
\hline Maintaining order in the nation is not given a high priority & higher number of police officers per 100,000 population
\end{tabular}

Figure 3. Differences between Indulgent and Restrained Societies

Source: Hofstede, 2011

In emerging countries, the dividend payout is fewer affected by national culture comparing with advanced countries. Furthermore, she indicated that good corporate governance decreases the influence of the culture. Furthermore, the study confirmed that this influence varies within emerging and advanced countries. The previous results were confirmed by (Halkos and Skouloudis, 2017) who investigated the relationship between corporate social responsibility (CSR) and the Hofstede cultural dimensions. The study concluded that culture forms the national and the characteristics of corporate social responsibility, and indulgence vs restraint positively influences on the CSR index. Thus, as the literature shows that the CSP interacted with indulgence and this interaction will influence on corporate financial performance. (hatmanu and et al., 2014) indicated that the business environment affected by practices of national culture, as a result, will impact on societal variables. The study also indicated that the acceptance of e-government in Romania may be affected by indulgence versus restraint.

Depend on the above studies it is noticed the important role of indulgence versus restraint as one of the cultural dimensions that play an effect on the business environment or on CSR. Later it will affect corporate financial performance.

Regarding Jordan's context as mentioned above that there are no studies conducted especially about this dimension. However, there are studies that addressed the cultural dimensions in general such as (Waqfi, 2004) who concluded that the culture of management is not the same in the Jordanian banks. As well as the managers are not recognizing the role of culture on performance. (Waqfi, 2004) recommended that if the managers understanding the culture that will be enhanced the bank performance. (Afaneh and et al., 2014) explored Hofstede's cultural dimensions in Jordanian private universities and their influence on the commitment of the organization. The researchers concluded that the managers are committed to the universities due to the managers tend to be collectivist. As well as the study found that Jordanian universities are categorized by the mutual of fourth cultural dimensions which influence on organizational commitment. The study stimulated the Jordanian universities to reconsider the culture. Such as teamwork in order to improve the performance. (Al-Harsh, 2008) examined the influence of Hofstede's cultural dimensions on the individuals in Jordanian commercial banks. The study concluded that individuals in Jordanian banks be likely to be collective and masculine in their actions. And they don prefer the Long-term orientation in the future. This study advises the Jordanian banks conducting Research \& Development activities and embracing selfgoverning applications to eliminate the factors that discourage innovation. 


\section{Indulgence vs. restraint in Jordan}

Based on mentioned above the Muslim world is considered a restraint culture. Therefore, Jordan scores (43) on the indulgence dimension that means that Jordan is not indulgent culture. People are bound by norms and society restricts the satisfaction of their needs (Hofstede website). Further, based on the findings of studies of the impact of indulgence on the corporate performance and according to classifications of Hofstede of the Arab world that indicated Jordan is restraint culture. It can be predicted that the indulgence dimension could be influenced negatively on corporate performance. This can be proved or denied when conducting empirical studies in Jordan.

\section{RESULTS AND DISCUSSION}

The Jordanian society has begun to enter the circle of modernity and undergoes transitional processes from traditional culture to a culture of openness. This transition from a traditional to a state of modernity and globalization has had a great impact on the individual culture and organizational culture of organizations. As the literature indicates that cultural dimensions influences on the behavior of individuals and later, as a result, may influence on the performance of companies. Therefore, this study reviews the literature related to the sixth dimension, indulgence versus restraint. Thus, after a survey of the literature of the Indulgence dimension and based on the discussion above we believe that there is a critical role of indulgence dimension on the performance. However, there are no conducted studies in Jordan regarding the Indulgence vs. restraint dimension.

\section{CONCLUSION AND RECOMMENDATION}

This paper contributes to the reference to the importance of this dimension as any other, and we believe based on research related to happiness, which showed that the indulgence societies feel free and full happiness and this reflected on their values and behaviour in a positive way, which positively affects the performance of the company. Where (Martins, M.M. and Lopes, I.T., 2016) indicated that a Higher Indulgence culture has a higher profitability. Therefore, due to this dimension is new, this paper emphasizes the importance of further research on this subject to enrich the literature of the Indulgence. Future research can improve or denied these results, since Hofstede and many studies have shown that the indulgence dimension influences behaviour.

\section{Recommendation}

Depending on the findings of studies that show the indulgence dimension impact on the performance of the company, the researcher recommends further research in Jordan to examine the impact of this dimension on the performance of Jordanian companies.

Furthermore, since the score of Hofstede's cultural dimensions vary across countries. So future comparison studies should be conducted in addition to the Jordan context.

\section{The importance of Future Research}

The current study could be the basis of further future researches regarding the Hofstede cultural dimensions of indulgence and its impact on performance in the Jordan context. Future research about this sixth cultural dimension and its impact on performance would be an opportunity for future studies as individual behaviour has an impact on the companies. Furthermore, further comparing studies would be valuable with other countries from the developing and developed countries. As Hofstede pointed out that the scores of Hofstede's dimensions are comparative, and it is useful to compare these societies. So conducting this research in Jordan's context and make comparisons with the other countries that differ in culture, would be more important. As the current study highlights the impact of indulgence on the performance, future studies should examine the impact of this dimension on the performance in the Jordan context and compare it with other countries (across countries). Future studies could be conducted on one of the big sectors in Jordan such as financial sectors as this sector form a large percentage 
of the economy in Jordan this could provide important and useful results for the policymakers.

\section{R E F E R E N C E}

Abu Asbah, Kh. (2012). Education for values in a society. A path for research and planning Strategy. Afaneh, J., Sanjuq, G., Khairreddin, M., \& Qaddoumi, J. (2014). Impact of cultural dimensions according to Hofstede model on organizational commitment of the middle management at Jordanian private universities. European Journal of Business and Social Sciences , 3, 129-146.

Al-Harsh, Nafez, Fayez. (2008). Measurement and Characterization of management and regulation in the Jordanian Environment Based on Hofstede's Cultural Dimensions: "case study" in Jordanian commercial banks, Jordanian Journal of Business Administration, Volume 4, Issue 3

Athreye, S., Batsakis, G., \& Singh, S. 2016. Local, global, and internal knowledge sourcing: The trilemma of foreign-based R\&D subsidiaries. Journal of Business Research, 69: 5694-5702.

Hofstede, Geert, Hofstede, Gert Jan, Minkov, Michael.(2010). Cultures and Organizations: Software of the Mind, Third Edition Paperback.

Hofstede website: http://geert-hofstede.com/national-culture.html

Hofstede, G. (2011). Dimensionalizing Cultures: The Hofstede Model in Context. Online Readings in Psychology and Culture, 2(1). https://doi.org/10.9707/2307-0919.1014

Halkos, George; and Skouloudis, Antonis. (2017).Revisiting the relationship between corporate social responsibility and national culture: a quantitative assessment. Management Decision, Vol. 55, Issue 3. pp. 595 - 613. ISSN 00251747 doi: https://doi.org/10.1108/MD1220160868. http://centaur.reading.ac.uk/70223/

Hatmanu, Mariana; Lobont, oana-ramona; Albu, crisan; and Moldovan, nicoleta-claudia. (2014). Impact of national culture on quality of governance development: the romanian reality, Economic Computation \& Economic Cybernetics Studies \& Research, Vol. 48 Issue 4, p59-79. 21p, Database: Business Source Premier

Oliveira, Ana Rita Camilo de. (2016). The Impact of Culture and Corporate Governance in Dividend Policy: Evidence from Emerging and Developed Countries, School of Technology and Management of the Polytechnic Institute of Leiria.

Schein, Edgar H. (1992). Organizational culture and leadership, 3rd ed. San Francisco: Jossey - Bass. Shi, Wei. and Veenstra, Kevin. (2015).The Moderating Effect of Cultural Values on the Relationship between Corporate Social Performance and Corporate Financial Performance, http:// capitalism.wfu.edu/wp-content/uploads/2015/04/K.-Veenstra-The-Moderating-Effect-ofCultural-Values-on-the-Relationship-between-Corporate-Social-Performance-and-CorporateFinancial-Performance.pdf

Sun, Jieqiong \& Yoo, Shijin \& Park, Jimi \& Hayati, Babak. (2018). Indulgence versus Restraint: The Moderating Role of Cultural Differences on the Relationship between Corporate Social Performance and Corporate Financial Performance. Journal of Global Marketing. 1-10. DO $-10.1080 / 08911762.2018 .1464236$.

Waqfi, Ali Awad .(2004). Development of the culture of the organization to improve institutional performance in the Jordanian commercial banks, unpublished Ph.D., Amman Arab University for Graduate Studies.

Enkh-Amgalan, R., 2016. The Indulgence and Restraint Cultural Dimension: A Cross-Cultural Study of Mongolia and the United States. 
Yaşar, Y.S., 2014. Dimensions of culture: Indulgence and restraint in academic life in Turkey. Unpublished master's thesis), Bahçeşehir University, Istanbul.

Martins, M.M. and Lopes, I.T., 2016. Culture and profitability: Empirical evidence at a European level. Culture and profitability: empirical evidence at a European level, (2), pp.579-586. 